\title{
Controlled climate comparisons of a tropical grass and legume
}

\author{
P. G. Tow \\ Department of Primary Industries Research Station, Kairi, Queensland, Australia \\ Received 1 September, 1966
}

\begin{abstract}
Summary
Glycine javanica cv. Tinaroo (glycine) and Panicum maximum var. trichoglume (green panic) were examined and compared by means of growth analysis, and by the measurement of transpiration coefficient and the response to seven different root temperatures. In the phytotron, overhead lighting was supplied at intensities below the saturation value for single leaves, and a method was used which enabled growth to be related to the amount of light intercepted by spaced plants.

It was found that green panic produced much more dry matter than glycine per unit of intercepted light and per unit of water transpired. Green panic also had higher shoot/root ratios than glycine.

Five other varieties of glycine were similar to Tinaroo in their efficiency of light utilization, but had consistently higher shoot/root ratios than Tinaroo.

Green panic made better growth than glycine when the temperature of a liquid root medium was raised above $30^{\circ} \mathrm{C}$.

Practical implications of the differences between the two species are discussed.
\end{abstract}

\section{Introduction}

In many parts of the tropical world, the productivity of grassland is being raised by the establishment of selected mixtures of tropical grasses and legumes. However, there is still not a great deal of basic information about the physiology of these species, and the way they react when grown in combination. In Queensland, Australia, a commonly-used pasture is a mixture of the grass Panicum maximum var. trichoglume (green panic) and the legume Glycine javanica cv. Tinaroo (glycine). These two species were chosen for use in a competition experiment carried out at the Institute for Biological and Chemical Research on Field Crops and Herbage (I.B.S.), Wageningen.

Before the competition experiment, a preliminary series of experiments was carried out to study and compare the behaviour of the two species by means of growth analysis. The species were grown apart in the phytotron at four air temperatures and three light intensities, and in one experiment, five other varieties of Glycine javanica were studied. In addition, a film was made of glycine leaf movements, the transpiration coefficients of the two species were measured, and comparisons were made of their growth at seven root temperatures.

These preliminary experiments are reported below. 


\section{Materials and methods}

Sand in small boxes was used as a medium for germination of the seed. The boxes were kept in the climate room, and at first covered with plastic to retain moisture. After germination had begun, the plastic was removed and the boxes watered to constant weight daily. The seedlings were transplanted when the first trifoliate leaf of the glycine was beginning to expand, and this coincided with the beginning of expansion of the third leaf of green panic. For transplanting, the sand was first flooded with water to reduce root damage during removal. The seedlings were then supported in half-Hoagland solution and continuous aeration was supplied throughout the experiment.

Two types of climate room were used, and facilities and methods peculiar to each will be discussed under the headings Growth analysis and Comparison of growth responses to different temperatures in the rooting medium.

\section{Growth analysis}

The phytotron consists of a series of rooms with varying air temperatures but otherwise identical climates. The two species were always grown simultaneously in the same room but on separate trolleys. One plant was supported over each one-litre container and except in the earliest experiments (see Results) the pots were kept widely spaced to avoid inter-plant shading.

The design of the phytotron, and the procedure for growing experimental plants in it have been outlined by Alberda (1958). The plants were subjected to a light intensity of about $5 \times 10^{4}$ ergs $\mathrm{cm}^{-2} \mathrm{sec}^{-1}$ from Philips 400 Watt HPL lamps, fitted in groups of six over each trolley-load of pots. The day-length was 17 hours, and the temperatures used were $15^{\circ}, 20^{\circ}, 25^{\circ}$ and $30^{\circ} \mathrm{C}$ (constant day and night). In one experiment, different thicknesses of cheese cloth were hung between the lamps and the plants to provide light intensities of $3.5 \times 10^{4}$ and $2.0 \times 10^{4} \mathrm{ergs}^{-2} \mathrm{sec}^{-1}$. This experiment was carried out at $25^{\circ} \mathrm{C}$ only, and the light intensity treatments were imposed from the time of transplanting. The experiment to compare five varieties of Glycine javanica was also carried out at $25^{\circ} \mathrm{C}$ only.

For growth analysis, 8 plants of each species were harvested each week, or occasionally more frequently if the size of the plants was becoming too great for the phytotron. Fresh and oven dry weights were determined separately for leaf, stem and root. The material was dried over-night in a forced draft oven at $70^{\circ} \mathrm{C}$, and then for an hour at $105^{\circ} \mathrm{C}$.

The plants received some set-back at transplanting and difficulty was often experienced with a marginal scorching of a proportion of young glycine leaves and some tip scorching of green panic (little of this occurred at the lower light intensities). Therefore, after the initial experiments, seedlings in excess of requirements were transplanted, and uniform material selected for the experiment after the effects of transplanting had worn off. It was then generally possible to grow the plants in the phytotron for only another two weeks. After this time they began to shade each other, or to grow out of the lamp light. In most cases, therefore, only three harvests were made, and where three intensities were used, only two harvests were made.

The net assimilation rate (NAR) is usually calculated by relating the growth rate of a plant to the area of its leaf surface. In a plant canopy, different leaves receive different intensities and qualities of light and it is difficult to know whether dif- 
ferences between species in NAR are due to internal differences in the efficiency of carbon assimilation, or to the effects of differences in the density and arrangement of leaves.

In the phytotron of the I.B.S., Wageningen, the light intensity is lower than the saturation value for single leaves of both species. Hence, the photosynthesis is proportional to the amount of intercepted light so that species can be compared best on this basis. As the light comes from directly above the plants, it was possible to obtain an estimate of light absorbed by estimating the area of green tissue seen in vertical projection. This was done by means of a viewing apparatus designed by H. J. Reints and A. J. Reestman (P.A.W., Wageningen, unpublished).

By this method the plants to be harvested on each occasion were placed under a $2 \mathrm{~cm} \times 4 \mathrm{~cm}$ grid over which a telescope was moved systematically. The plants were viewed through the telescope, and an area of $8 \mathrm{~cm}^{2}$ was recorded whenever a piece of green tissue intercepted the cross-wires of the eyepiece. The total area recorded for each harvest was called the light interception area (LIA). In most cases, a duplicate estimate of LIA was made after re-arranging the plants on the trolley beneath the telescope.

From the total dry weight (TDW in grams), light interception area (LIA in $\mathrm{cm}^{2}$ ), and time ( $T$, in days after germination), the following calculations were made:

Relative growth rate $(\mathrm{RGR})=\left(\ln \mathrm{TDW}_{2}-\ln \mathrm{TDW}_{1}\right) /\left(T_{2}-T_{1}\right)$

Light interception ratio $($ LIR) $=$ LIA/TDW

Net assimilation rate on a light interception basis (NARI) $=$

$$
\frac{\mathrm{TDW}_{2}-\mathrm{TDW}_{1}}{\mathrm{LIA}_{2}-\mathrm{LIA}_{1}} \times \frac{\ln \mathrm{LIA}_{2}-\ln \mathrm{LIA}_{1}}{T_{2}-T_{1}}
$$

\section{Leaf movements}

In the case of glycine, leaf movements occurred regularly every day, and care had to be taken that LIA measurements were made when the leaves were in the normal, fully displayed position. (Measurements on green panic were made at the same time.) The glycine leaves drooped some time before the dark period, and became virtually horizontal again shortly after the lights came on. In order to study these movements, a cine film was made of growing plants by an automatic camera photographing once every 6 min during the light period. These plants were grown at $25^{\circ} \mathrm{C}$ in the phytotron described under Growth analysis.

\section{Transpiration coefficient}

For estimation of transpiration coefficient, 4 plants were grown in each one-litre container, and transpiration was measured by weighing each container minus piants before and after the nutrient solution was changed three times weekly. Tests showed that the normal lid supporting the plants over the solution prevented measurable evaporation of water. Dry matter production was estimated by subtracting the oven dry weight of 12 plants of each species at the start of the experiment from that of the remainder ( 40 of each species) 9 days later. The transpiration coefficient was calculated by dividing the amount of water transpired during these 9 days by the dry weight produced. The plants were grown at $25^{\circ} \mathrm{C}$ in the phytotron described under Growth analysis. 


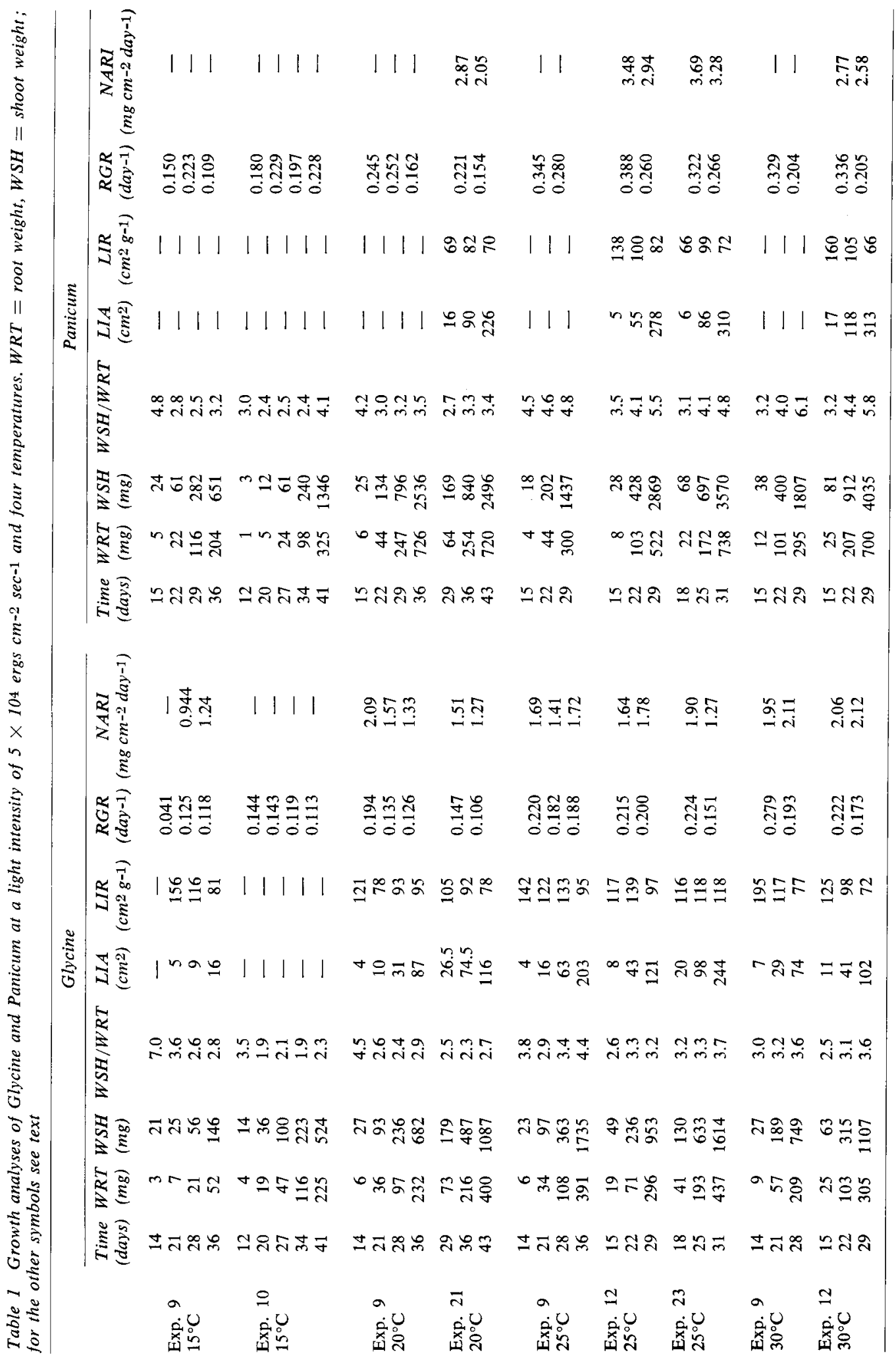


Comparison of growth responses to different temperatures in the rooting medium This experiment was carried out three times in growth rooms lit by fluorescent lamps, and with a 17-hour day-length. Each room was fitted with a series of containers for nutrient solution with temperature control for $10^{\circ}, 15^{\circ}, 20^{\circ}, 25^{\circ}, 30^{\circ}, 35^{\circ}$ and $40^{\circ} \mathrm{C}$. In order to compare the two species over this range of temperature, two rooms had to be used. One had a constant air temperature of about $26^{\circ} \mathrm{C}$ and a relative humidity of $60-70 \%$; the other had a constant air temperature of about $28^{\circ} \mathrm{C}$, and a relative humidity of about $50 \%$. In case these conditions had different effects on the two species, each was grown at least once in each room.

The seedlings were transplanted a week after germination. Two harvests were made at an interval of about a week.

No attempt has been made to compare the species directly for dry matter production, as self-shading occurred between the group of plants in each container, and this would have varied for each species at each temperature. The main aim was to compare their curves of response to the various root temperatures for total plant growth, as well as the components, leaf, stem and root.

\section{Results}

The experiments have been numbered as in the computer result sheets.

The glycine and green panic germinated simultaneously at each temperature, so comparisons of the two species have been made with plants of the same age. However, at the time of transplanting, the legume plants invariably had a much greater dry weight than the grass plants because of differences in seed size. Glycine never developed root nodules, and so relied solely on the nutrient solution for its nitrogen. Neither species flowered at the 17 hour day-length.

Growth analysis

Except for the two initial, exploratory experiments, the results of all experiments carried out are presented in Table 1-3. Some inter-plant shading may have occurred in experiment 9, at least in the final stages, but from experiment 10 onwards, a good deal of care was taken to avoid this by spacing the pots wider apart as the plants increased in size. Limitations of space in the phytotron made this difficult, especially in the final stages of experiments and in experiment 27 where extra treatments were included, it is suspected that slight inter-plant shading may have occurred with the fastest growing plants.

Response by green panic to different temperatures and light intensities. Between $20^{\circ}$ and $25^{\circ} \mathrm{C}$ there was a clear increase in the RGR, which appeared to be due principally to higher values of NARI rather than of LIR. There was no clear indication of an increase in $\mathrm{RGR}$ between $15^{\circ}$ and $20^{\circ} \mathrm{C}$, or between $25^{\circ}$ and $30^{\circ} \mathrm{C}$, and the only measurement of NARI at the extreme temperatures (Experiment $12,30^{\circ} \mathrm{C}$ ) suggested that the NARI was lower at $30^{\circ}$ than at $25^{\circ} \mathrm{C}$.

Difficulties were experienced with green panic at $30^{\circ} \mathrm{C}$, as the leaves failed to unroll at their tips during expansion, and this resulted in necrosis of a large section of the leaf blade. The damage was avoided in experiment 12 by raising the relative humidity to about $90 \%$ by means of a misting machine. At $30^{\circ} \mathrm{C}$, also, leaf and stem tissue elongated and spread so fast, that 4 weeks after germination the green panic 


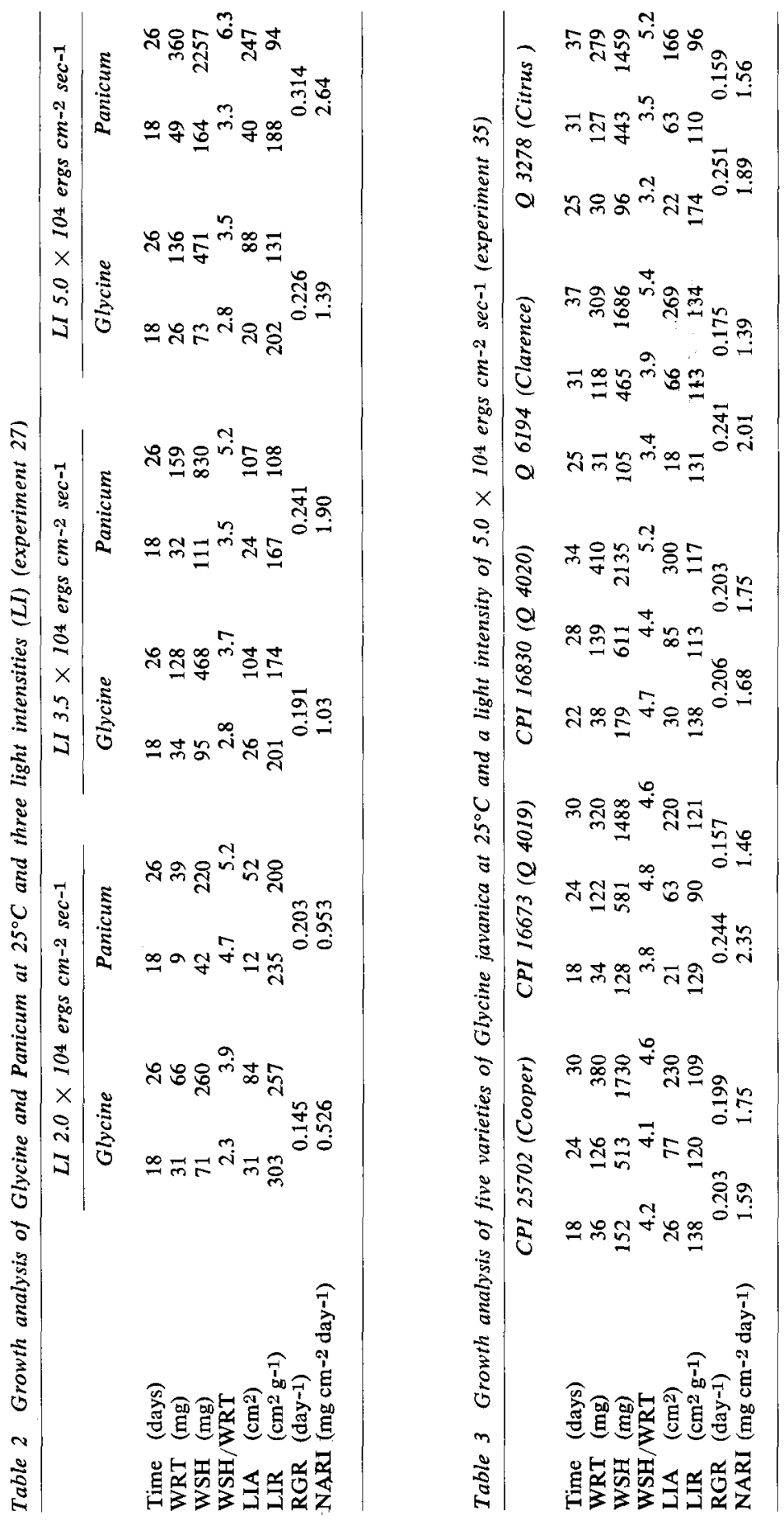



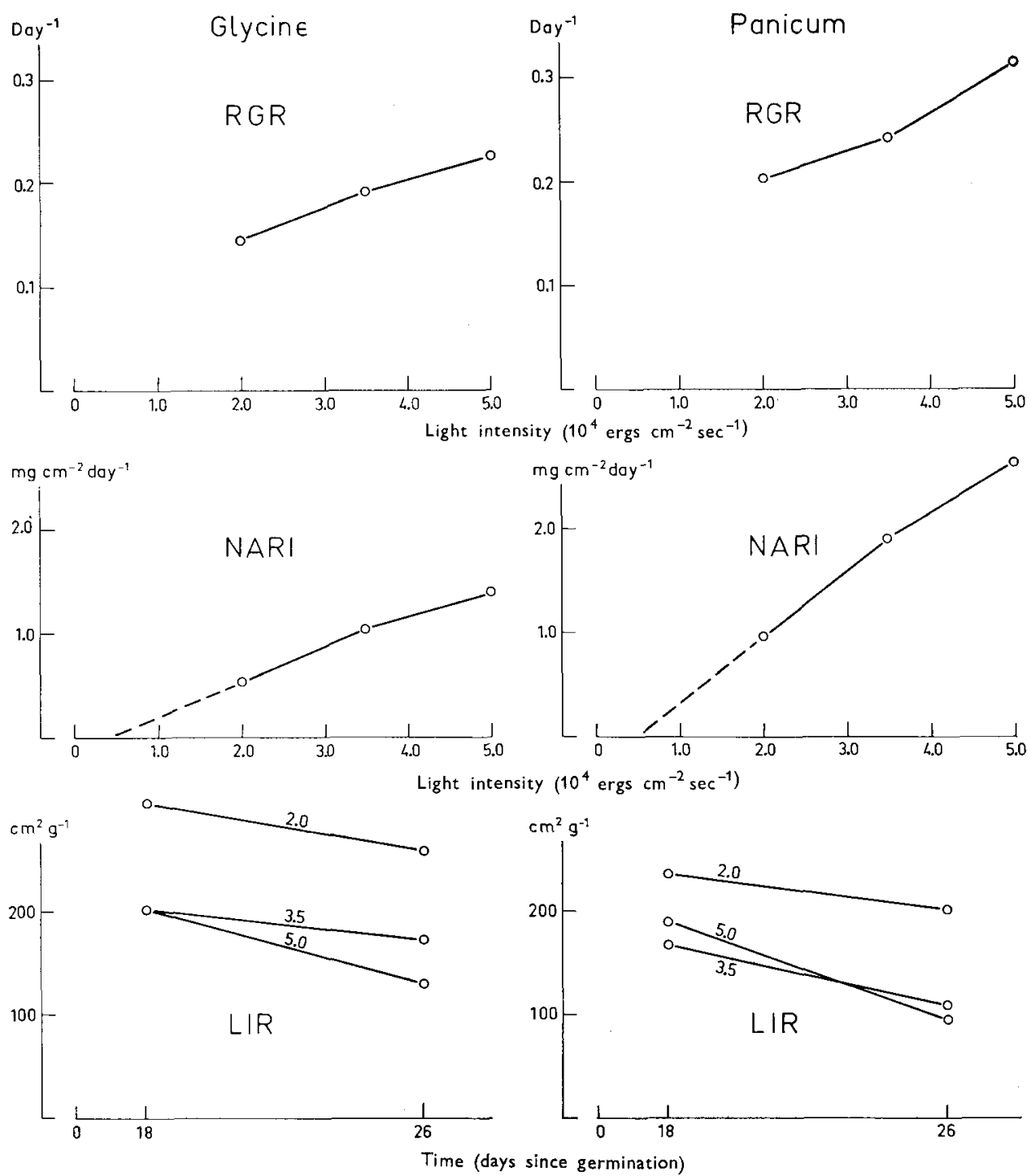

Fig. I Response of Glycine and Panicum to seven root temperatures. Air temperature $28^{\circ} \mathrm{C}$, relative humidity $50 \%$.

plants were too tall and wide-spreading to be accommodated satisfactorily beneath the lamps. Time prevented further refinements in technique from being made to see if higher RGR's could be achieved.

Decreasing light intensity at $25^{\circ} \mathrm{C}$ resulted in lower values of $R G R$ due to lower NARI. In general, LIR increased with decreasing light intensity, but this could not compensate for the lower NARI (Table 2). Fig. 1 shows that the estimate of NARI 
at a light intensity of 50,000 ergs $\mathrm{cm}^{-2} \mathrm{sec}^{-1}$ is a little lower than required for a linear response to light intensity, and is also a little lower than estimates from other experiments obtained at this temperature and light intensity (Table 1). As already stated, this may have been due to inter-plant shading.

Time trends: In almost all experiments, RGR decreased with time. This can be explained by both the NARI and the LIR decreasing with time. At $15^{\circ} \mathrm{C}$ (experiment 10 ) the decline with time was not present, but at this low temperature, transplanting setbacks were especially common, and this may have prevented the young plants from attaining the initially high values of NARI found in the other experiments.

The shoot/root ratio was practically always highest at the first harvest but this was probably due to loss of roots at transplanting. The other data are rather irregular but a few tendencies can be observed. The shoot/root ratio increased with increasing temperature, at least up to $25^{\circ} \mathrm{C}$. The temperature effect is complicated by an increase in the ratio with time, a trend that appears more marked at the higher temperatures. As with the NARI, the most marked changes with temperature occurred between $20^{\circ}$ and $25^{\circ} \mathrm{C}$. Thus at $20^{\circ} \mathrm{C}$ a plant with an oven dry weight of just over $3 \mathrm{~g} \mathrm{had}$ a shoot/root ratio of about 3.5 , while a plant of similar size at $25^{\circ} \mathrm{C}$ had a ratio of around 5 , and a similar value at $30^{\circ} \mathrm{C}$. Occasional high values in small plants were probably due to loss of roots at transplanting. Decreasing light intensity at $25^{\circ} \mathrm{C}$ resulted in lower shoot/root ratios initially, but at the second harvest, the ratio was high at all three intensities, especially at the highest.

The response of glycine to different temperatures and light intensities. In general, RGR was higher at the higher temperatures though variation in estimates prevented the attainment of distinct, large differences for each $5^{\circ}$ rise. Variations are at least partly due to a decline in RGR with time and the fact that comparisons between experiments are made with plants of slightly different age and size.

In general, also, NARI increased with temperature, the main anomaly being a high early estimate at $20^{\circ} \mathrm{C}$ (experiment 9). In most experiments there was very little decline in NARI with time, and sometimes even an increase. The decline in LIR with time was not very great, except at $30^{\circ} \mathrm{C}$.

Transplanting set-backs were less severe at lower light intensities, so that at the first harvest, the weight of plants grown at $3.5 \times 10^{4} \mathrm{ergs}^{-2} \mathrm{sec}^{-1}$ was little different from that at $5 \times 10^{4}$ ergs $\mathrm{cm}^{-2} \mathrm{sec}^{-1}$. Decreasing light intensity at $25^{\circ} \mathrm{C}$ resulted in lower RGR due to lower NARI. In general, LIR increased with decreasing light intensity, but this could not compensate for the lower NARI (Table 2). Fig. 1 shows that the estimate of NARI at a light intensity of $5 \times 10^{4}$ ergs $\mathrm{cm}^{-2} \mathrm{sec}^{-1}$ is slightly lower than expected for a linear response to light intensity, and a little lower than the other values obtained at $25^{\circ} \mathrm{C}$ at that light intensity (Table 1). As also with green panic in this experiment, some slight inter-plant shading is suspected in the later stages, at the highest light intensity.

The shoot/root ratio increased with increasing temperature up to $25^{\circ} \mathrm{C}$, but on only one occasion (Table 1, experiment 9) did it exceed a value of 4 . The values also increased slightly with time, apart from the initial phase where adjustment to transplanting was taking place. At lower light intensities, the ratio was lower at the first harvest, but at the second harvest it was higher with decreasing light.

Comparisons between glycine and green panic. The various tables show clearly that 

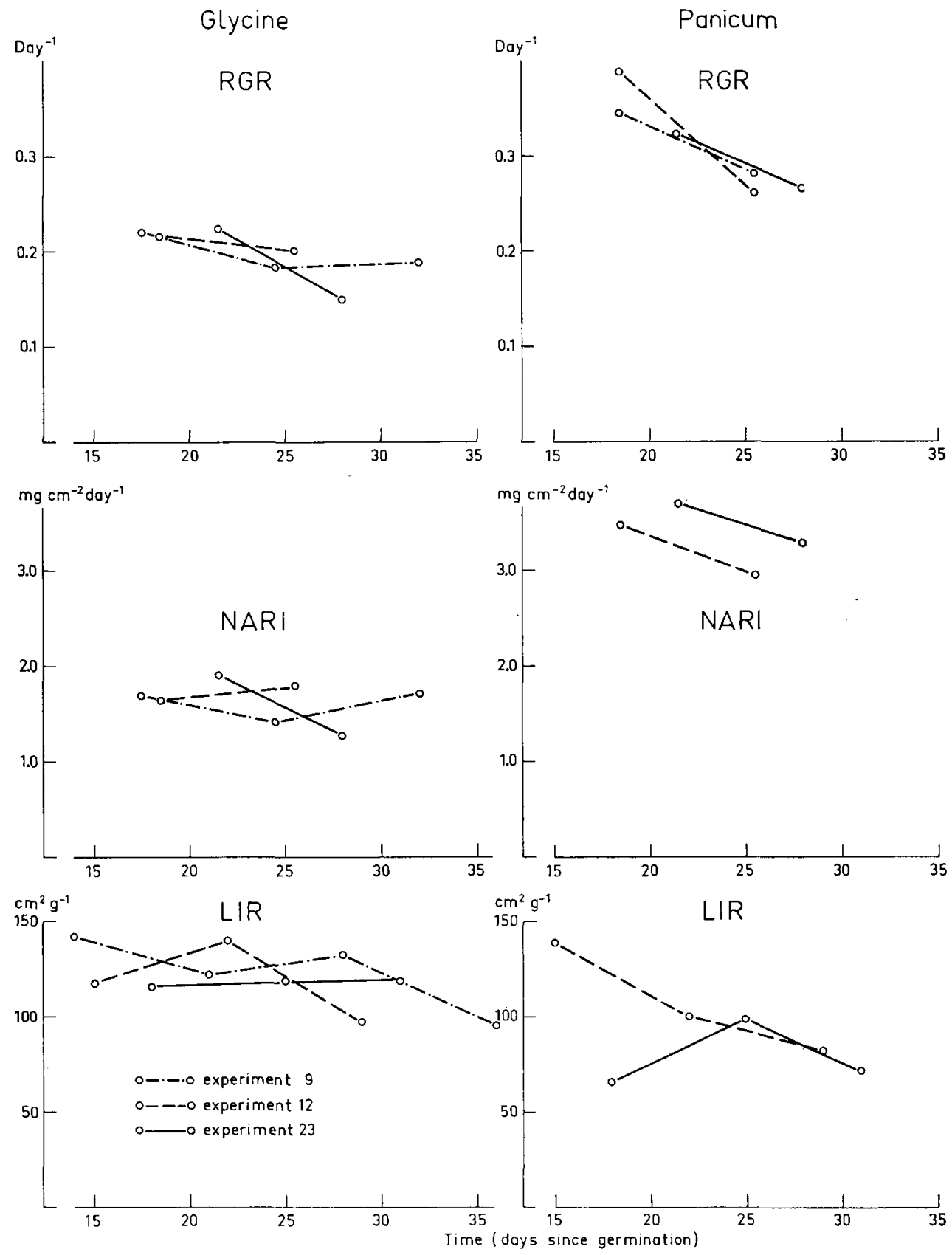

Fig. 2 Growth analysis of Glycine and Panicum at $25^{\circ} \mathrm{C}$ and a light intensity of $5 \times 104$ ergs $\mathrm{cm}-2 \mathrm{sec}-1$. 
for each time interval at each temperature, green panic had a higher RGR than glycine. The only exception is one estimate in experiment $9,15^{\circ} \mathrm{C}$, and inter-plant shading has already been suggested for this experiment.

NARI was not estimated for green panic at $15^{\circ} \mathrm{C}$, but for the other temperatures, the higher RGR for the grass was clearly due to a higher NARI. The differences were most marked at $25^{\circ} \mathrm{C}$ (see also Fig. 1 and 2). NARI continued to increase to $30^{\circ} \mathrm{C}$ in the case of glycine, but not in the case of green panic. The decline with time in RGR and NARI was more marked for green panic than for glycine.

LIR did not differ much between the two species, and if anything, it was higher for the legume than the grass at any one time.

At all temperatures, too, the grass had the higher shoot/root ratio, differences becoming especially marked at the later harvests and the higher temperatures.

Five other varieties of Glycine javanica at $25^{\circ} \mathrm{C}$. The values for RGR and NARI were all similar to those for Tinaroo glycine, and so below the values for green panic. (Table 3). Some strains had higher initial values than were recorded for the Tinaroo strain, but in those cases, the values for the following time interval were much lower. LIR values were also similar to those obtained for the Tinaroo strain, but shoot/root ratios were consistently higher in these strains than for Tinaroo; there were many examples of shoot/root ratios over 4 , and some over 5 , i.e. in the range obtained for green panic.

It was also found that the varieties varied in leaf size and in effectiveness of display of leaves to the lamplight. However, the experiment was not detailed enough to allow small differences to be measured.

\section{Glycine growth movements}

By means of the films made of Tinaroo glycine growth, it was calculated that the leaves were in the drooped position for about 5 hours of the total 17 light hours. Immediately after the lamps switched on the leaves placed themselves rapidly in a horizontal position and approximately 5 hours before the lamps switched off they gradually drooped to the nearly vertical position.

Transpiration coefficients

The data, and the calculations made from them are shown in Table 4.

Table 4 Relation between dry matter production and water usage

\begin{tabular}{lcc}
\hline & Panicum & Glycine \\
Dry matter production per pot $(\mathrm{g})$ & 3.329 & 2.070 \\
Water usage per pot $(\mathrm{g})$ & 676.5 & 774.0 \\
Transpiration coefficient & 203 & 374 \\
Dry matter production per g water (mg) & 4.9 & 2.7 \\
\hline
\end{tabular}

The transpiration coefficient was over $80 \%$ higher in glycine than in green panic. Green panic therefore produced about $80 \%$ more dry matter per unit of water than glycine.

Growth response to seven root temperatures

Since the results did not appear to be influenced by change in aerial environment, the data of only two experiments are presented in Fig. 3. 


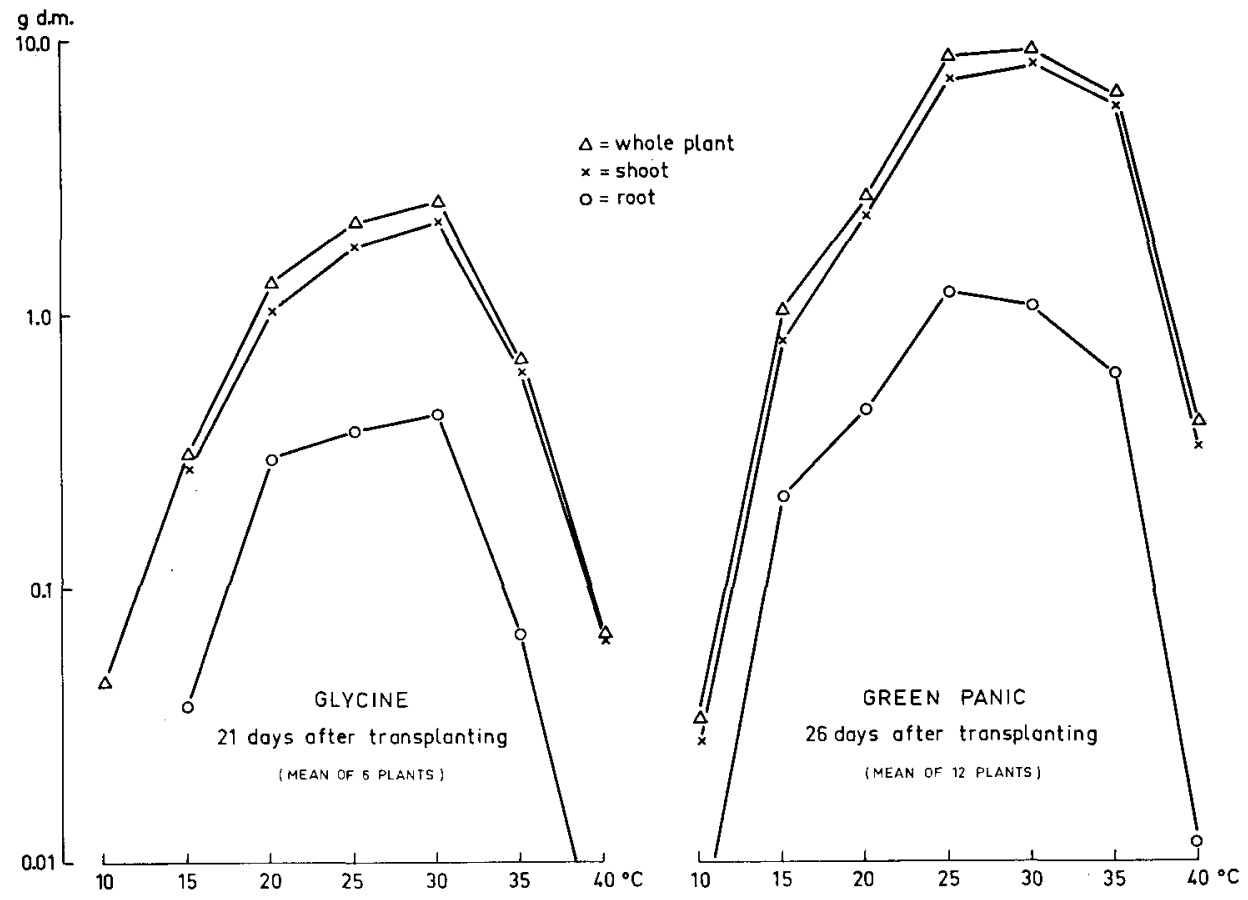

Fig. 3 Growth analysis of Glycine and Panicum at $25^{\circ} \mathrm{C}$ and three light intensities.

Virtually no growth occurred in either species at a root temperature of $10^{\circ} \mathrm{C}$, and there was a marked increase in plant dry matter, with increasing temperature, up to $30^{\circ} \mathrm{C}$ in both species.

At higher temperatures, there was consistently less dry matter production, but the response to these temperatures was different in the two species. For glycine, dry matter production at $35^{\circ}$ root temperature was much less than that produced at $25^{\circ} \mathrm{C}$. For green panic, however, dry matter production at $35^{\circ}$ root temperature was only a little less than at $25^{\circ} \mathrm{C}$. Such a difference between the two species represents a large percentage of dry matter response. In addition, some growth of green panic occurred with a $40^{\circ} \mathrm{C}$ root temperature (apparently after a period of adjustment). None occurred in glycine at $40^{\circ} \mathrm{C}$.

Fig. 3 shows that the relative rate of response to increasing root temperature was higher for the shoot than for the root in both species, or, where there was a decline at the higher temperatures, this decline was greater in the root than the shoot. Thus, the shoot/root ratio increased with increasing root temperature. In glycine, this increase appeared to occur from $20^{\circ} \mathrm{C}$. The starting temperature is less clear in the case of green panic in Fig. 3, but when the data of the other experiments are also examined in logarithmic form (not shown here) it appears that the starting point for green panic was about $20^{\circ} \mathrm{C}$ also.

The dry matter content of all parts of the plant was markedly lower at intermediate 
temperatures than at the extremes (data not shown). At $10^{\circ}$ and $15^{\circ} \mathrm{C}$, the region of the lower stem and the upper root of glycine became thickened, while at $35^{\circ} \mathrm{C}$ the roots began to grow in the nutrient solution, but then stopped and developed a knobbly appearance at the ends. These effects were not apparent in the roots of green panic. An interveinal chlorosis in the leaves of green panic was corrected by adding sulphuric acid to bring the $\mathrm{pH}$ of the nutrient solution to 4.5 , then adding $1.5 \mathrm{ml}$ per litre of $0.003 \mathrm{M}$ ferrous sulphate.

\section{Discussion}

By relating the growth rate of the two species in the phytotron to the amount of below-saturation intensity light intercepted, it has been possible to show that green panic makes more efficient use of light for photosynthesis than does glycine. In addition, the ratio NARI green panic/NARI glycine is about the same as the ratio for their dry matter production per unit of transpired water. This being so, the transpiration per unit of intercepted light would be the same for the two species. Thus, from the points of view of production capacity and efficiency of water use, green panic is the superior species.

The light interception method of growth analysis can be assessed further by examining some of the data in graph form, and also by comparing them with known values of photosynthesis for single leaves.

The easiest temperature at which to grow these plants in the phytotron was $25^{\circ} \mathrm{C}$, and it was here that it was possible to carry out two full repetitions of the growth analysis of green panic and three of glycine, in the time available. The growth analyses of Tinaroo glycine and green panic at this temperature are illustrated in Fig. 1 and 2. In Fig. 2, it is seen that there was some variation among the various experiments in the estimates of RGR. This would have been due to experimental error, or slight variations in technique throughout the period of several months. However, the technique was adequate to ensure distinct and consistent differences between the two species, as had already been discussed under Results. In the case of NARI estimates, the amount of variation among experiments was similar to the variation for RGR, and with the use of the light interception method the distinct differences between the two species for NARI largely explained the differences in RGR. The species differences were still apparent when Tinaroo glycine was replaced by five other varieties of Glycine javanica. In the case of LIR estimates, there was no distinct difference between species, though even here there is some reason for suggesting that glycine generally had higher values than green panic, for spaced plants.

Fig. 1 is consistent with the other data in showing that the two species exhibited two distinct curves of response to below-saturation light intensities, green panic having the steeper slope for its NARI curve. By extrapolating the curves to the X-axis, a value is obtained for the compensation point. This is about $0.5 \times 10^{4} \mathrm{erg} \mathrm{cm}^{-2} \mathrm{sec}^{-1}$ for each species, which seems a reasonable figure. The increase in LIR at lower light intensities is analagous to an increase in leaf area ratio (LAR), which is often found. Gaastra's $(1959,1962)$ data give photosynthesis rates of $140 \mathrm{~mm}^{3} \mathrm{CO}_{2} \mathrm{~cm}^{-2} \mathrm{~h}^{-1}$ for single leaves of sugar beet at high light intensites. This is equivalent to $34 \times 10^{-4}$ $\mathrm{g} \mathrm{cm}^{-2} \mathrm{day}^{-1}$ for a 17-hour daylength. Estimates of NARI for glycine and green panic lay within the range of $15 \times 10^{-4}$ to $35 \times 10^{-4} \mathrm{~g} \mathrm{~cm}^{-2} \mathrm{day}^{-1}$, and rates for photosynthesis would presumably be $20-50 \%$ higher. Thus the light interception method 
of estimating NARI gave values of the same order as those for photosynthesis of single sugar beet leaves by the method of gas analysis.

By using light interception area in place of leaf area, differences in leaf arrangement have been excluded as possible causes of the differences in net assimilation rate. It might be possible that the drooping or sleeping habit of glycine leaves during part of the light period was accompanied by a reduction or cessation of photosynthesis, and thus a lower average NARI. Assuming that photosynthesis was at a standstill in glycine for 5 hours of light, NARI could be calculated for a 12-hour day instead of a 17 hour one. This would increase the estimate by about $30 \%$; whereas NARI of green panic was approximately $80 \%$ higher than that of glycine.

Legumes expend appreciable amounts of energy on nitrogen fixation (Wilson, 1940). In the present experiments, however, glycine was not nodulated, so nitrogen fixation cannot be held responsible for even a part of the inferiority of glycine in net photosynthesis.

This relatively high capacity of green panic for dry matter production would be apparent under field conditions as well as in the phytotron, and is indeed supported by general experience at the Kairi Research Station and elsewhere. As shown by de Wit (1965), the photosynthesis function (including photosynthetic efficiency as one of its components) is by far the most important factor influencing dry matter production of leaf canopies. Leaf arrangement is comparatively much less important, though if anything, incident light will be more efficiently used by a closed canopy of fairly erect grass leaves than by a closed canopy of fairly horizontal legume leaves. Green panic should have even greater advantage over glycine in the field.

In the present experiments, green panic also had much higher shoot/root ratios than Tinaroo glycine, and the differences between the two widened with time and with increase in temperature. Thus, from the point of view of the production of aboveground dry matter, green panic was still further superior to Tinaroo glycine, especially at high temperatures. However, there was some indication that at $30^{\circ} \mathrm{C}$, where green panic attained shoot/root ratios of about 6 , its NARI was actually lower than at $25^{\circ} \mathrm{C}$. On the other hand, NARI had improved between $20^{\circ}$ and $25^{\circ} \mathrm{C}$; and for glycine, it continued to improve right up to $30^{\circ} \mathrm{C}$. The reasons for these types of behaviour are not known. An interesting feature of the other varieties of Glycine javanica was that most of them attained much higher shoot/root ratios than Tinaroo. All other factors being equal, this could be interpreted as greater vigor under conditions where roots are not harvested, as in the field.

Finally, green panic showed its superiority over glycine with regard to its reaction to high temperatures in a liquid root medium. Root temperatures above $30^{\circ} \mathrm{C}$ caused a reduction in growth in both species, but there was less severe reduction in the grass than in the legume. No attempt was made to find the actual root temparature, for each species, at which the response in growth to increasing temperature became negative. In the field high surface soil temperatures may affect seedling growth, but once the plants have roots in deeper, cooler soil layers, the hot surface may not have much effect. Any thorough study of growth at extreme temperatures should probably also take into account the process of hardening.

One of the main reasons for including legumes in a pasture is for their ability to grow by the use of symbiotically-fixed atmospheric nitrogen. The present experiments show that the advantage of nitrogen fixation in glycine mus $\downarrow$ be considered over against the greater efficiency with which green panic can make use of light and water, and its superiority in some other ways. In some situations, efficiency of light and water 
use can be more important than nitrogen fixation. Legumes may have other advantages in a pasture, e.g. as donors of nitrogen to associated grass, and as contributors towards a more effective stock ration than is provided by grass alone. The various advantages and disadvantages of legumes and grasses must be carefully assessed in deciding on the most useful and economic type of pasture for a particular environment or need.

When green panic and glycine are grown together, as is often the case in practice, the superiority of the grass as seen in the present experiments may also give it an initial competitive advantage over the legume. Such an initial competitive advantage has been described by de Wit et al. (1966), but it was also shown that competitive interactions between grasses and legumes eventually become quite complicated. The present experiments are important mainly from the point of view of determining basic characteristics of the species, which may be used to assist in explaining and comparing their behaviour in the field.

\section{Acknowledgements}

The author is greatly indebted to the International Agricultural Centre, Wageningen, The Netherlands, for a scholarship and to the Queensland Department of Primary Industries for leave and assistance, to enable this project to be carried out. I wish to thank Professor Dr. Ir. G. J. Vervelde, Director of the I.B.S., Wageningen, for kind permission to work at the Institute; Dr. Ir. C. T. de Wit for valuable ideas and guidance in planning the growth analysis experiments, and also for electronic computation of the results; Dr. Th. Alberda and Dr. R. Brouwer for providing controlled environment facilities and the benefit of their experience; L. Sibma and L. ten Holten, Miss L. R. Eijer, Miss M. J. de Kock and Mrs. E. C. la Maitre-van de Peppel for technical assistance at various stages of the work.

\section{References}

Alberda, Th., 1958. The phytotron of the Institute for Biological and Chemical Research on Field Crops and Herbage at Wageningen. Acta Botan. Neerl., 7 : 265-277.

Gaastra, P., 1959. Photosynthesis of crop plants as influenced by light, carbon dioxide, temperature and stomatal diffusion resistance. Meded. Landbouwhogesch., Wageningen, 59 (13).

Gaastra, P., 1962. Photosynthesis of leaves and field crops. Neth. J. Agric. Sci., $10(5): 311-324$.

Wilson, P. W., 1940. The biochemistry of symbiotic nitrogen fixation. Univ. Wisconsin Press, Madison, Wisc., U.S.A.

Wit, C. T. de, 1965. Photosynthesis of leaf canopies. Versl. Landbouwk. Onderz., 663.

Wit, C. T. de, Tow, P. G. and Ennik, G. C., 1966. Competition between legumes and grasses. Agric. Res. Rept., 687. 